\title{
Protective effect of maternal vitamin E supplementation on phenytoin-induced teratogenicity in rat pups
}

\author{
Tarek M. Essa ${ }^{1}$, Attia M. Gabr ${ }^{2}$, Abd El-Rahman E. Mohamed ${ }^{3}$, Abdel-Raheim M. A. Meki ${ }^{4}$ \\ ${ }^{1}$ Department of Anatomy and Embryology, Faculty of Medicine, Alexandria University, Alexandria, Egypt \\ ${ }^{2}$ Department of Pharmacology, Faculty of Medicine, Swiss Canal University, Cairo, Egypt \\ ${ }^{3}$ Department of Anatomy and Embryology, Faculty of Medicine, Cairo University, Cairo, Egypt \\ ${ }^{4}$ Department of Biochemistry, Faculty of Medicine, Assiut University, Assiut, Egypt
}

\begin{abstract}
Objectives: Phenytoin teratogenicity is induced by embryonic hypoxia as a result of generation of reactive oxygen species. Antioxidants are effective in treating conditions associated with oxidative damage. This study investigated the possible protective effect of vitamin E maternal supplementation on oxidative damage, and the morphological and morphometric changes induced by phenytoin in pups.

Methods: Five groups of female rats were utilized. All the treatments were injected intraperitoneal. Groups I and II were injected with saline and olive oil, respectively. Group III was injected with vitamin E (0.5 g/kg BW/day) from day one to day 20 of gestation. Group IV was injected with phenytoin (150 mg/kg BW/day) from day 6 to day 18 of gestation. Group V was injected with phenytoin and vitamin $\mathrm{E}$. The $\mathrm{N}$-acetyl D-glucosaminidase, malondialdehyde, and glutathione were determined as markers of tissue damage. The skeletons of pups were examined after staining with alizarin red-S.

Results: Phenytoin significantly increased oxidative stress indices in maternal plasma and tissues and in pup tissues. This was associated with a significant decrease in the weight, length and number of pups. Moreover, there were maxillary hypoplasia and skeletal anomalies. Co-administration of vitamin E with phenytoin reduced oxidative damage with significant increase in the weight, length and number of pups. Reduction in maxillary hypoplasia and skeletal anomalies were observed.

Conclusion: Vitamin E maternal supplementation has significant effect in the reduction of the anomalies induced by phenytoin in pups.
\end{abstract}

Keywords: maxillary hypoplasia; oxidative stress; phenytoin; rats; skeletal anomalies; teratogenicity; vitamin E

Anatomy 2015;9(1):1-12 (02015 Turkish Society of Anatomy and Clinical Anatomy (TSACA)

\section{Introduction}

Exposure of the developing embryo or fetus to certain chemical agents and drugs is known to produce congenital anomalies leading to in-utero death or structural birth defects commonly termed teratogenesis. ${ }^{[1]}$ Various forms of embryonic malformation have been attributed to oxidative stress. ${ }^{[2]}$ Oxidative stress is a deleterious process that results in damage of cellular components. ${ }^{[3]}$ It results from inappropriate production of free oxygen radicals or failure of the cell to detoxify a normal free radical load or both. There has been a compelling evi- dence linking teratogens such as phenytoin (PHT) to reactive oxygen species (ROS). ${ }^{[4,5]}$

PHT as a hydantoin derivative is used for control of epilepsy; epileptic patients taking PHT as monotherapy or receiving multiple drugs ${ }^{[6,7]}$ PHT therapy has been associated with enhanced oxidative stress in experimental animals. ${ }^{[8-12]}$ PHT has been documented to be a teratogenic agent in both mice and rats. ${ }^{[13]}$ It is believed that PHT produces anomalies in $34 \%$ of fetuses which are exposed to it. ${ }^{[14]}$ Cleft lip (CL) is a common malformation that has both genetic and exogenous causes. The main 
pharmaceutical cause of CL is exposure to PHT during early facial development in the 5th to 6th weeks of gestation. ${ }^{[15]}$ PHT administration in the pregnant rats has an effect on the growth of the upper lip of their fetuses that result in maxillary hypoplasia (short upper lip). In these fetuses, the maxillary processes appear reduced and meet in the midline to a reduced extent. ${ }^{[16]}$

Previous studies suggested that PHT teratogenicity is induced by embryonic hypoxia with vascular disruption and tissue necrosis as a result of ischemic damage and/or ROS generation at reoxygenation. ${ }^{[9]} \mathrm{PHT}$ causes bradycardia in rat embryos. ${ }^{[17]}$ There is considerable evidence that PHT-induced birth defects in the rat are a consequence of a period of bradycardia and hypoxia in the embryos. ${ }^{[16]}$

PHT is thought to cause chronic intrauterine hypoxia / ischemia and embryo - fetal toxicity via oxidative stress. ${ }^{[18]}$ ROS can oxidize molecular targets such as DNA, proteins and lipids in a process referred to as oxidative stress, resulting in-utero death or teratogenicity. The pathology of oxidative stress can be prevented by antioxidants known to be effective in treating conditions associated with oxidative damage. ${ }^{[19]}$

Vitamin E (Vit E), a natural antioxidant, is believed to help in amelioration of diseases associated with oxidative stress. ${ }^{[20]}$ Vit E supplementation is able to ameliorate the PHT-induced oxidative stress in the brain of rats. ${ }^{[1]}$ Toxicity of Vit E is very low and adverse effects are rarely observed at dosages up to $2000 \mathrm{mg}$ /day in human subjects. At much higher dosages, side effects and intolerance have been noted. The only consistent side effect of Vit $\mathrm{E}$ treatment was coagulation abnormalities in individuals with previous vitamin $\mathrm{K}$ deficiency ${ }^{[20]} \mathrm{Vit} \mathrm{E}$ is considered safe in pregnancy, although experiments evaluating the safety of high-doses of Vit $\mathrm{E}$ treatment in pregnancy have not been reported. ${ }^{[2]]}$ The fact that premature infants have poorly developed antioxidant systems lends special relevance to the study of antioxidant protection in preterm rat. ${ }^{[9,22,23]}$

The present study was conducted to evaluate the changes in the oxidative stress indices induced by the anticonvulsant PHT on the pregnant rats and their pups' tissues. The relationship between these biochemical changes and the morphological and morphometric changes in the pups were also assessed. Moreover, this study also aimed at assessing the protective effect of maternal Vit E supplementation on the status of oxidative stress indices; and the morphological and morphometric changes in the pups.

\section{Materials and Methods}

\section{Chemicals}

Thiobarbituric acid, butylated hydroxytoluene, reduced glutathione, sodium sulphate, epinephrine, 5',5'-dithiobis2-nitro-benzoic acid; 5,5-diphenylhydantion (phenytoin) and vitamin $\mathrm{E}$ were purchased from Sigma (St. Louis, MO, USA). All other chemicals used were of analytical grade.

\section{Animal treatment}

Fifty healthy adult virgin female Sprague-Dawley rats (about 175-200 g body weight) were utilized in this study. The rats were housed in the animal facility, Faculty of Medicine, Qassim University, Saudi Arabia. The experimental protocol followed the "Guide for Care and Use of Laboratory Animals" prepared by The National Academy of Sciences. All animals were conditioned at room temperature at a natural photoperiod for one week before experiment execution. A commercial balanced diet and tap water ad libitum were provided.

The female rats were mated with adult male rats of the same strain in a ratio of three females with one male rat in one cage. ${ }^{[2]]}$ Next morning each female rat was examined for any sign of mating in the form of blood stained vagina or a vaginal plug. ${ }^{[25,26]}$ The presence of any sign of mating is considered as day zero of pregnancy. Absence of any apparent sign of mating led to vaginal wash which was obtained on glass slide and observed under microscope for presence of spermatozoa. Their presence was again considered as day zero of pregnancy. ${ }^{[16]}$

The pregnant rats were separated from male rats and randomly divided into five groups (each containing 10 rats). The rats received all treatments (PHT, Vit E, olive oil and saline) via intraperitoneal (IP) injection. PHT was dissolved in saline and Vit $\mathrm{E}$ was dissolved in olive oil. The extra virgin olive oil was purchased from Al Jouf region, Sakaka, Saudi Arabia.

Group I (Control group) rats were injected IP with normal saline in a dose $0.1 \mathrm{ml} /$ day from day 1 to day 20 of gestation. Group II (oil group) rats were injected IP with olive oil in a dose $0.1 \mathrm{ml} /$ day from day 1 to day 20 of gestation. Group III (Vit E group) rats were injected IP with Vit $\mathrm{E}$ in a dose $0.5 \mathrm{~g} / \mathrm{kg}$ body weight (BW)/day, dissolved in $0.1 \mathrm{ml}$ of olive oil from day 1 to day 20 of gestation. Group IV (PHT- group) rats were injected IP with PHT in a dose of $150 \mathrm{mg} / \mathrm{kg}$ BW/day dissolved in $0.1 \mathrm{ml}$ saline from day 6 to day 18 of gestation. Group V (PHT+Vit E group) rats were injected IP with PHT in a dose 150 $\mathrm{mg} / \mathrm{kg} \mathrm{BW} /$ day from day 6 to day 18 of gestation and Vit $\mathrm{E}(0.5 \mathrm{~g} / \mathrm{kg}$ BW/day) from day 1 to day 20 of gestation.

The mothers of different groups received light anesthesia just after delivery. Blood sample from each rat was collected from the orbital vein in heparinized tubes. The 
blood samples were centrifuged at $5000 \mathrm{rpm}$ for $10 \mathrm{~min}$ for plasma separation. The obtained plasma was divided into aliquots and kept at $-26^{\circ} \mathrm{C}$ until biochemical analyses. The animals were sacrificed and the livers and brains were excised immediately for biochemical investigations. The tissues were homogenized in ice-cold $100 \mathrm{mM}$ phosphate buffer ( $\mathrm{pH}$ 7.4) using a Potter-Elvehjem homogenizer fitted with a Teflon Plunger. Tissues homogenates were centrifuged at $11,000 \mathrm{~g}$ for $20 \mathrm{~min}$ and resulting supernatants were divided into aliquots and stored at $-80{ }^{\circ} \mathrm{C}$.

The living pups received light anesthesia just after delivery and were examined regarding their number, weight and crown-rump length. The total number of pups born to each of the studied groups was 101 for group I, 104 for group II, 101 for group III, 87 for group IV and 97 for group V. The crown-rump length was measured using a Vernier Swiss caliber with $0.01 \mathrm{~mm}$ accuracy, and the weight was measured using an electric balance. The pups were sacrificed and their livers, kidneys and hearts were excised immediately for biochemical investigations. Each studied organ was taken from all pups of each mother of the same group, pooled as one sample and homogenized in ice-cold $100 \mathrm{mM}$ phosphate buffer ( $\mathrm{pH}$ 7.4) using a Potter-Elvehjem homogenizer fitted with a Teflon Plunger. Tissue homogenates were centrifuged at 11,000 $\mathrm{g}$ for $20 \mathrm{~min}$ and the resulting supernatants were divided into aliquots and stored at $-80{ }^{\circ} \mathrm{C}$.

The pups were then eviscerated and fixed in 10\% neutral buffered formaldehyde for one week and examined for cleft lip and maxillary hypoplasia. ${ }^{[27]}$ The length of the region where the maxillary processes meet in the midline was measured in the pups of all groups using a stereomicroscope [Leica EZ HD (Leica Microsystems GmbH, Wetzlar, Germany) $]^{[16]}$ In the control group, this length ranged from 1.67 to $2.14 \mathrm{~mm}$. Pups of the other groups were classified as having maxillary hypoplasia if this length was less than $1.67 \mathrm{~mm}$. After one week, the pups were processed through 95\% ethanol and acetone then placed in $4 \% \mathrm{KOH}$ for a period of 1-2 weeks for clearing. ${ }^{[25]}$ After clearing, they were bulk stained using $0.001 \%$ alizarin red in $1 \% \mathrm{KOH} \cdot{ }^{[28]}$ This technique clearly demonstrated the ossified bone while the unossified bone remained unstained. Thereafter, a transparency process was implemented to visualize the ossified bones.

Stained pups were put in $1 \% \mathrm{KOH}$ for one day, then put in $80 \mathrm{ml} \mathrm{1 \%} \mathrm{KOH}$ and $20 \mathrm{ml} \mathrm{20 \%} \mathrm{glycerin} \mathrm{for} 5$ days, then put in $50 \mathrm{ml} 1 \% \mathrm{KOH}$ and $50 \mathrm{ml} 50 \%$ glycerin for 5 days, and then put in $20 \mathrm{ml} \mathrm{1 \%} \mathrm{KOH}$ and $80 \mathrm{ml} 80 \%$ glycerin for 5 days. ${ }^{[29-31]}$ Thereafter, they were transferred into pure glycerin. ${ }^{[13]}$ The transparent pup specimens were observed under a stereomicroscope (Leica EZ HD) to determine the malformations. Photographs were taken using the stereomicroscope camera and Sony 14 megapixels camera.

\section{Biochemical analysis}

Total proteins levels in tissue homogenates were determined by the method of Lowry et al..$^{[32]}$ using a commercial kit (Sclavo Diagnostics, Sovicille SI, Italy) The levels of malondialdehyde (MDA) were measured as described by Thayer. ${ }^{[33]}$ The reduced glutathione (GSH) levels were determined chemically as described by Dutta et al. ${ }^{[34]}$ The lysosomal N-acetyl D - glucosaminidase (NAGA) activity was determined using kit purchased form Sigma Company (Cat No. CS0780).

\section{Statistical analysis}

The results were expressed as mean \pm standard error (SE). Differences between groups were assessed by one-way analysis of variance, ANOVA using the Prism version 5 software package for Windows. The level of significance was accepted with $\mathrm{p} \leq 0.05$.

\section{Results}

\section{Biochemical findings}

Mean levels of MDA, GSH and NAGA in maternal plasma and tissues are shown in Tables 1 and 2. MDA and NAGA activities in both brain and liver tissues as well as in plasma of PHT-treated group were elevated signifi-

Table 1

Plasma levels (mean values) of malondialdehyde (MDA), glutathione (GSH) and enzyme N-acetyl-glucosaminidase (NAGA) in different treated groups of female rats.

\begin{tabular}{|c|c|c|c|c|c|}
\hline Variables & Controls & $\begin{array}{l}\text { Olive oil- } \\
\text { group }\end{array}$ & $\begin{array}{l}\text { Vit E- } \\
\text { group }\end{array}$ & $\begin{array}{l}\text { PHT- } \\
\text { group }\end{array}$ & $\begin{array}{c}\text { PHT+Vit E- } \\
\text { group }\end{array}$ \\
\hline $\operatorname{MDA}(\mathrm{nmol} / \mathrm{ml})$ & $1.935 \pm 0.09689$ & $1.735 \pm 0.1062$ & $1.835 \pm 0.1307$ & $3.332 \pm 0.3619 * *$ & $1.866 \pm 0.04752^{+\dagger}$ \\
\hline $\mathrm{GSH}(\mathrm{nmol} / \mathrm{ml})$ & $4.672 \pm 0.2248$ & $5.022 \pm 0.2159$ & $4.195 \pm 0.2764$ & $2.323 \pm 0.2147 * * *$ & $3.192 \pm 0.1644^{* * *}, \dagger$ \\
\hline NAGA $(\mathrm{mM} / \mathrm{min} / \mathrm{ml})$ & $2.297 \pm 0.1838$ & $2.512 \pm 0.1844$ & $1.678 \pm 0.2121 *$ & $4.873 \pm 0.5109 * * *$ & $1.301 \pm 0.1934^{* *},+\dagger$ \\
\hline
\end{tabular}


Table 2

Tissue levels (mean value) of malondialdehyde (MDA), glutathione (GSH) and enzyme N-acetyl-glucosaminidase (NAGA) in different treated groups of female rats.

\begin{tabular}{|c|c|c|c|c|c|c|}
\hline Variables & Tissues & Controls & $\begin{array}{l}\text { Olive oil- } \\
\text { group }\end{array}$ & $\begin{array}{l}\text { Vit E- } \\
\text { group }\end{array}$ & $\begin{array}{l}\text { PHT- } \\
\text { group }\end{array}$ & $\begin{array}{c}\text { PHT+Vit E- } \\
\text { group }\end{array}$ \\
\hline \multirow[t]{2}{*}{ MDA (nmol/mg protein) } & Liver & $2.158 \pm 0.05304$ & $1.793 \pm 0.2598$ & $1.793 \pm 0.2598$ & $3.162 \pm 0.1745^{* *}$ & $2.616 \pm 0.3266$ \\
\hline & Brain & $3.340 \pm 0.2435$ & $2.700 \pm 0.3277$ & $2.546 \pm 0.2126^{*}$ & $5.029 \pm 0.7115^{\star}$ & $2.574 \pm 0.1397^{*}, \dagger$ \\
\hline \multirow[t]{2}{*}{ GSH (nmol/mg protein) } & Liver & $29.19 \pm 2.015$ & $34.30 \pm 3.291$ & $28.64 \pm 1.899$ & $18.01 \pm 1.875^{\star *}$ & $27.45 \pm 2.118^{\dagger}$ \\
\hline & Brain & $16.20 \pm 0.6837$ & $16.87 \pm 0.7329$ & $16.78 \pm 0.7364$ & $11.54 \pm 0.6846$ ** & $14.46 \pm 0.6000^{\dagger}$ \\
\hline \multirow[t]{2}{*}{ NAGA (mM/min/g protein) } & Liver & $7.345 \pm 0.2998$ & $8.117 \pm 0.4301$ & $6.172 \pm 0.4975$ & $12.58 \pm 0.6285^{* *}$ & $8.791 \pm 0.2134 * *,+\dagger$ \\
\hline & Brain & $1.449 \pm 0.1618$ & $1.795 \pm 0.2212$ & $1.902 \pm 0.1969$ & $3.508 \pm 0.2289 * *$ & $2.780 \pm 0.1036 * *,+$ \\
\hline
\end{tabular}

$*: p<0.05 ; * *: p<0.001$ for comparison of all studied groups versus controls. ${ }^{+}: p<0.01,{ }^{++}: p<0.001$.

cantly in comparison to controls. The MDA levels in brain tissues and in plasma of PHT + Vit E-treated group showed a significant reduction compared to the PHTtreated group. NAGA activity in brain and liver tissues and in plasma of PHT + Vit E-treated group showed a significant reduction in comparison with PHT-treated group. The levels of GSH in both brain and liver tissues as well as in plasma of the PHT-treated group were reduced significantly compared to controls. The levels of GSH in brain and liver tissues and in plasma of PHT + Vit E treated group were significantly higher than PHTtreated group.

Levels of MDA and GSH, and NAGA activities in pup tissues are shown in Table 3. The levels of MDA and NAGA activities in liver, kidney and heart tissues in pups of PHT treated rats were significantly elevated in comparison with those of control group pups. The levels of MDA in all tissues of pups of the PHT + Vit E-treated group showed a significant reduction as compared to those in pups of PHT-treated group. Similarly, the NAGA activi- ties in liver and heart tissues of pups of the PHT + Vit Etreated group showed a significant reduction as compared to those in pups of PHT-treated group. The levels of GSH in tissues of pups of PHT-treated group were reduced significantly in comparison to those in pups of control group. The levels of GSH in liver and kidney tissues were significantly higher in pups of PHT + Vit Etreated group than corresponding levels in pups of the PHT-treated group.

\section{Morphological and morphometric findings}

Weight, crown-rump length and number of pups are shown in Table 4 and Figure 1. The mean weight of the pups born to control group and PHT-treated group were $5.60 \pm 0.10 \mathrm{~g}$ and $4.06 \pm 0.10 \mathrm{~g}$, respectively. The mean weight of the pups born to PHT + Vit E-treated group was $5.31 \pm 0.10 \mathrm{~g}$. The weight of the pups of PHTtreated group was significantly lower than those born to control and PHT + Vit E-treated groups.

Table 3

Tissue levels (mean values) of malondialdehyde (MDA), glutathione (GSH) and enzyme N-acetyl-glucosaminidase (NAGA) in different treated groups of rat pups.

\begin{tabular}{|c|c|c|c|c|c|c|}
\hline Variables & Tissues & Controls & $\begin{array}{l}\text { Olive oil- } \\
\text { group }\end{array}$ & $\begin{array}{l}\text { Vit E- } \\
\text { group }\end{array}$ & $\begin{array}{l}\text { PHT- } \\
\text { group }\end{array}$ & $\begin{array}{l}\text { PHT+Vit E- } \\
\text { group }\end{array}$ \\
\hline \multirow[t]{3}{*}{ MDA (nmol/mg protein) } & Liver & $2.380 \pm 0.2404$ & $2.080 \pm 0.2011$ & $1.782 \pm 0.1855$ & $3.221 \pm 0.1526^{* *}$ & $2.125 \pm 0.2202^{t+\dagger}$ \\
\hline & Kidney & $1.762 \pm 0.2741$ & $1.582 \pm 0.2536$ & $1.462 \pm 0.2328$ & $2.886 \pm 0.09811 * *$ & $2.191 \pm 0.2495^{\dagger}$ \\
\hline & Heart & $2.188 \pm 0.2274$ & $1.843 \pm 0.2911$ & $1.775 \pm 0.2321$ & $3.144 \pm 0.1274^{* *}$ & $2.067 \pm 0.2378^{t+\dagger}$ \\
\hline \multirow[t]{3}{*}{ GSH (nmol/mg protein) } & Liver & $29.70 \pm 2.226$ & $31.96 \pm 1.941$ & $29.59 \pm 0.9847$ & $21.44 \pm 1.837^{*}$ & $30.90 \pm 1.649^{+\dagger}$ \\
\hline & Kidney & $22.66 \pm 1.563$ & $24.33 \pm 2.057$ & $23.75 \pm 2.463$ & $14.58 \pm 0.7571 * * *$ & $20.34 \pm 2.288^{+}$ \\
\hline & Heart & $21.43 \pm 1.359$ & $21.03 \pm 1.538$ & $20.61 \pm 0.9074$ & $16.52 \pm 0.4453^{* *}$ & $17.09 \pm 0.5383^{* *}$ \\
\hline \multirow[t]{3}{*}{ NAGA (mM/min/g protein) } & Liver & $6.436 \pm 0.4531$ & $6.789 \pm 0.4765$ & $7.231 \pm 0.3902$ & $10.20 \pm 0.5221 * * *$ & $8.566 \pm 0.2003 * * *,+\dagger$ \\
\hline & Kidney & $1.935 \pm 0.1238$ & $1.558 \pm 0.1413$ & $1.692 \pm 0.09722$ & $3.313 \pm 0.2242 * * *$ & $2.584 \pm 0.2777^{*}$ \\
\hline & Heart & $0.7987 \pm 0.1209$ & $0.8544 \pm 0.05553$ & $0.8978 \pm 0.1086$ & $2.869 \pm 0.09676^{* * *}$ & $1.494 \pm 0.08489 * * *,+十 \dagger$ \\
\hline
\end{tabular}

$*: p<0.05 ;{ }^{* *}: p<0.01 ;{ }^{* *}: p<0.001$ for comparison for comparison all studied groups versus controls. ${ }^{+}: p<0.05 ;{ }^{+t}: p<0.01 ;{ }^{t+t}: p<0.001$ for comparison of PHT+Vit E-treated group versus PHT-treated group. 
Table 4

Mean values of the weight, length and number of pups for different treated groups of female rats.

\begin{tabular}{|c|c|c|c|c|c|}
\hline Variables & Controls & $\begin{array}{l}\text { Olive oil- } \\
\text { group }\end{array}$ & $\begin{array}{l}\text { Vit E- } \\
\text { group }\end{array}$ & $\begin{array}{l}\text { PHT- } \\
\text { group }\end{array}$ & $\begin{array}{l}\text { PHT+Vit E- } \\
\text { group }\end{array}$ \\
\hline Total number of pups & 101 & 104 & 101 & 87 & 97 \\
\hline Weight of pups (gm) & $5.599 \pm 0.1049$ & $5.686 \pm 0.09848$ & $5.689 \pm 0.09818$ & $4.062 \pm 0.1036^{* *}$ & $5.317 \pm 0.1039^{+\dagger}$ \\
\hline Crown-rump Length $(\mathrm{cm})$ & $4.429 \pm 0.04173$ & $4.502 \pm 0.02869$ & $4.355 \pm 0.03976$ & $3.880 \pm 0.08018^{* *}$ & $4.212 \pm 0.0361 * *,+\dagger$ \\
\hline Number of pups & $10.10 \pm 0.4333$ & $10.60 \pm 0.4269$ & $10.10 \pm 0.3480$ & $8.700 \pm 0.2603^{*}$ & $9.700 \pm 0.3958^{+}$ \\
\hline
\end{tabular}

The mean crown-rump length of the pups born to control group and PHT-treated group were $4.43 \pm 0.04 \mathrm{~cm}$ and $3.88 \pm 0.08 \mathrm{~cm}$, respectively. The mean crown-rump length of the pups born to PHT + Vit E treated group was $4.21 \pm 0.04 \mathrm{~cm}$. The crown-rump length in the pups born to PHT-treated group was significantly lower than those born to control and PHT + Vit E-treated groups.

The number of the pups born to each mother in control group ranged from 8 to 12 with a mean of $10.1 \pm 0.43$. The number of the pups born to each mother of the PHT-treated group ranged from 8 to 10 with a mean of $8.7 \pm 0.26$. The number of the pups born to each mother in the PHT + Vit E-treated group ranged from 8 to 11 with a mean of $9.7 \pm 0.39$. The number of the pups born to the PHT-treated group was significantly lower than those born to control and PHT + Vit E treated groups.

Maxillary hypoplasia was noted in the pups born to the PHT-treated group, observed in 12 pups out of 87 (13.79\%) (Figure 2). In the pups of the PHT + Vit E- treated group, maxillary hypoplasia was found in five pups out of 97 (4.6\%). There was no maxillary hypoplasia in the pups of olive oil and Vit E-treated groups.

Examination of the skeleton of the pups in the control group showed that the maxilla, premaxilla, nasal, frontal, parietal and occipital bones; mandible were mostly ossified and stained red in all pups (Figures 3a and $\mathbf{b}$ ). The main body of the scapula was ossified (Figure 4a). The body, arch and part of the spinous processes of all the vertebrae, except the caudal ones, were ossified (Figures 4 and 5a). All ribs were mostly ossified (Figures $5 \mathbf{a}$ and $\mathbf{b}$ ). Diaphysis of long bones of the extremities was ossified (Figure 6). The calcaneus, pisiform, the four metacarpal and the five metatarsal bones, the proximal and distal phalanges were ossified (Figures $7 \mathbf{a}$ and $\mathbf{b}$ ). There were 6 ossified sternebrae (Figure 8a). The skeleton of the pups in olive oil and Vit E-treated groups was similar to that of pups in the control group.
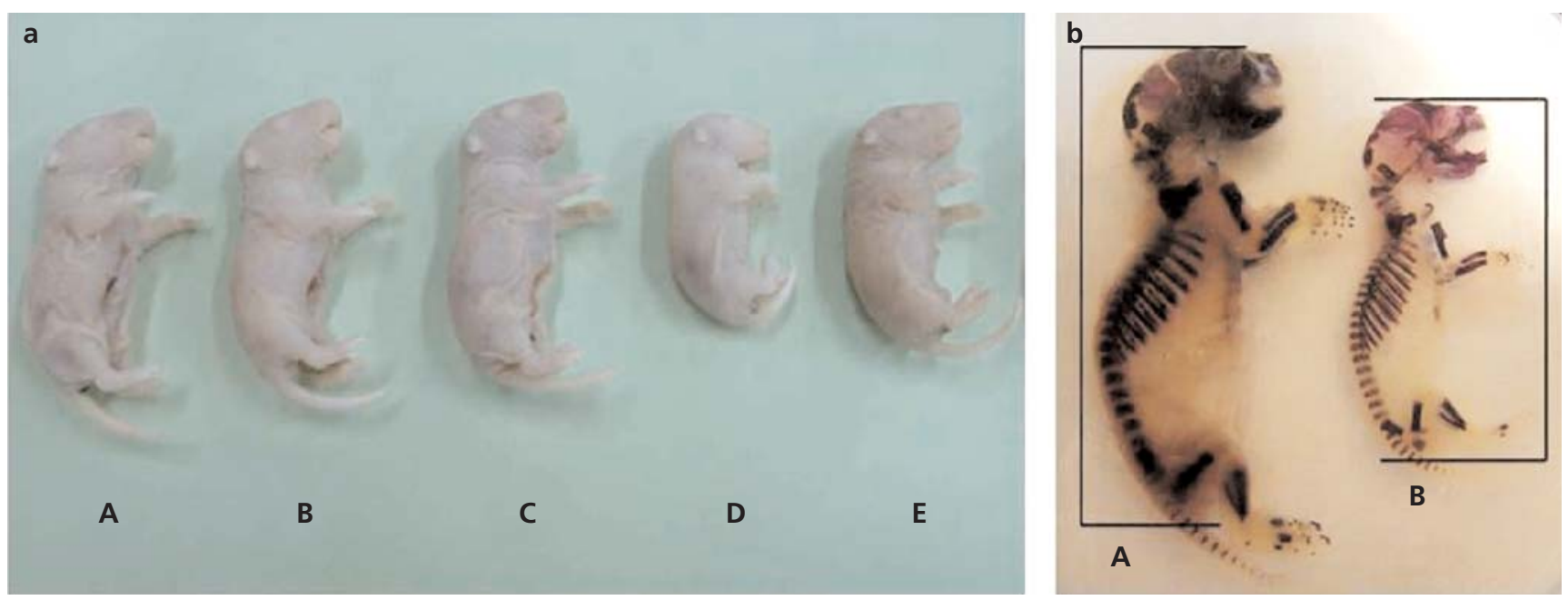

Figure 1. (a) A photograph of the pups of different treated groups of female rates showing growth retardation of the pup of the PHT treated female rat. A: Pup born to control group; B: Pup born to olive oil treated group; C: Pup born to Vit E treated group; D: Pup born to PHT treated group; E: Pup born to PHT + Vit E treated group. (b) A photograph of the skeletons of a pup born to control female rat (A) and a pup born to PHT treated female rat (B) stained with alizarin red-S showing much less crown-rump length of the PHT treated skeleton. 

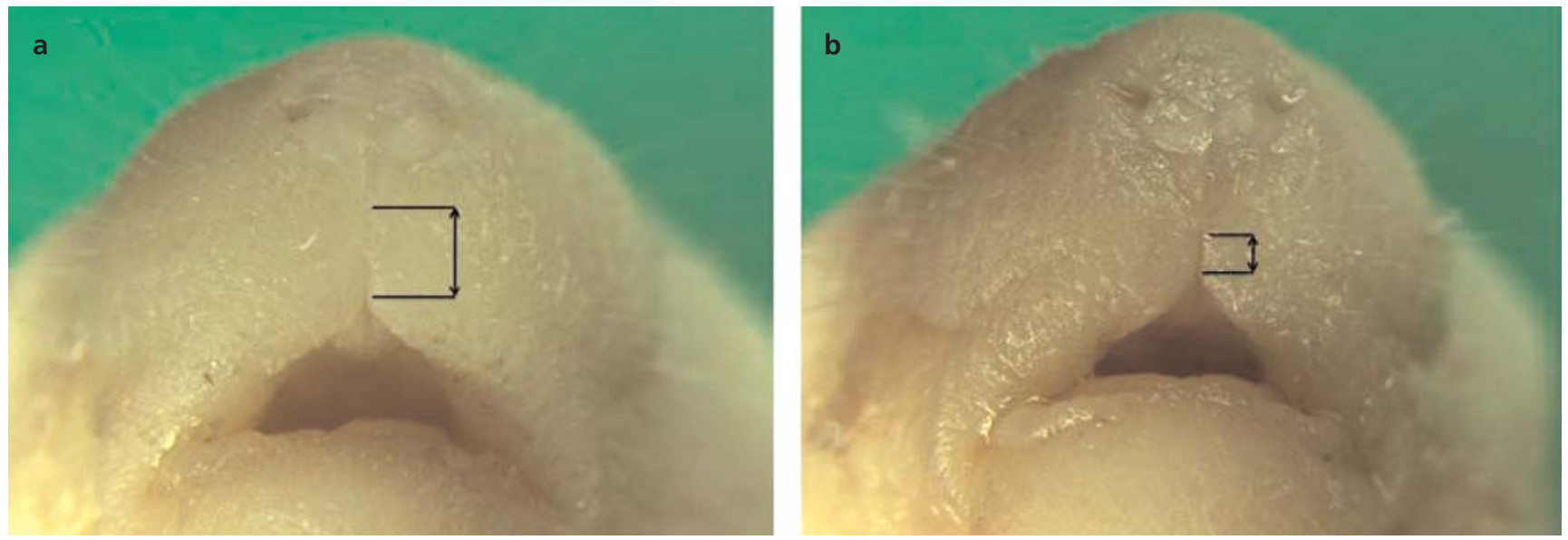

Figure 2. (a) A photograph of a pup born to control female rat showing the normal extent of the contact between the two maxillary processes in the midline (double-headed arrow). (b) A photograph of a pup born to PHT treated female rat showing maxillary hypoplasia; the two maxillary processes have only small area of contact in the midline (double-headed arrow).

In the pups of the PHT-treated group, the skull bones showed mild ossification in 39 pups out of 87 (48\%) (Figure 3c). Costal anomalies in the form of separation between the ribs and fusion of the posterior ends of the shaft of two adjacent ribs were observed in seven pups out of $87(8 \%)$ and in four pups out of $87(4.6 \%)$, respectively (Figures 5c and d). Delayed or lack of ossification was observed in the bones of the hand and foot in 23 pups out of $50(26.4 \%)$ (Figures $7 \mathbf{c}$ and $\mathbf{d})$. In six pups out of 87 (6.9\%), there were five ossified sternebrae (Figure 8b). Lumbar scoliosis was seen in five pups out of 87 (5.7\%) (Figure 9).

In the pups of the PHT + Vit E-treated group, there was mild ossification in the skull bones in 9 pups out of $97(17.5 \%)$. Delayed or lack of ossification were
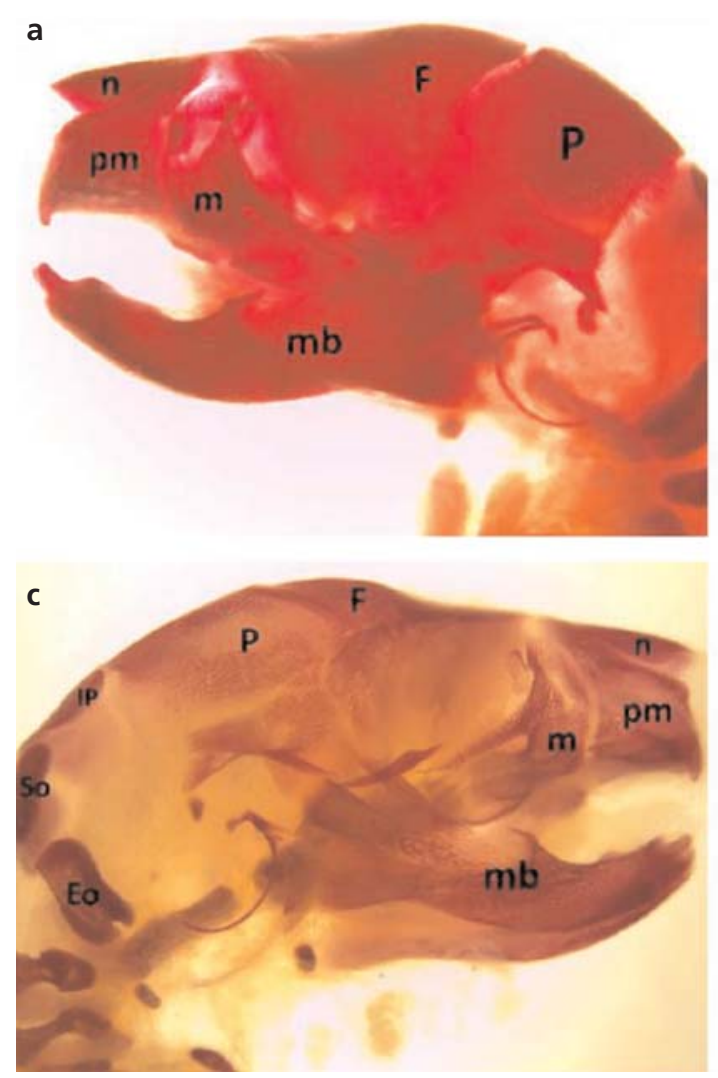

b

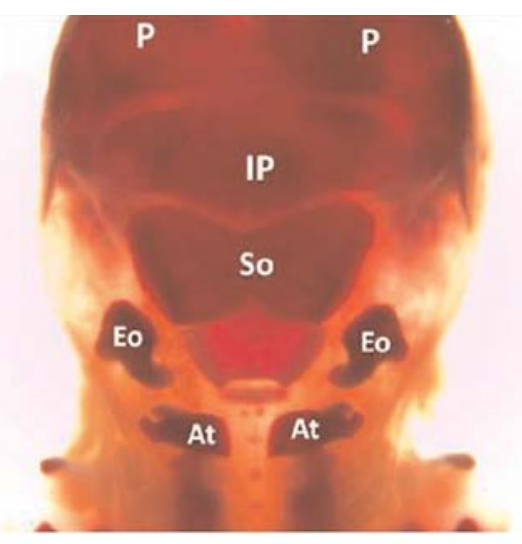

Figure 3. Lateral (a) and posterior (b) views of the skull of pups born to control female rats stained with alizarin red-S showing ossified maxilla $(m)$, premaxilla $(\mathrm{pm})$, nasal $(\mathrm{n})$, frontal $(\mathrm{F})$, parietal $(\mathrm{P})$ bones, interparietal (IP), superoccipital (So), exoccipital (Eo) parts of the occipital bone and atlas vertebra (At). The mandible (mb) is also ossified. (c) Lateral view of the skull of a pup born to PHT treated female rat stained with alizarin red-S showing mild (faint) ossification of the skull bones. 

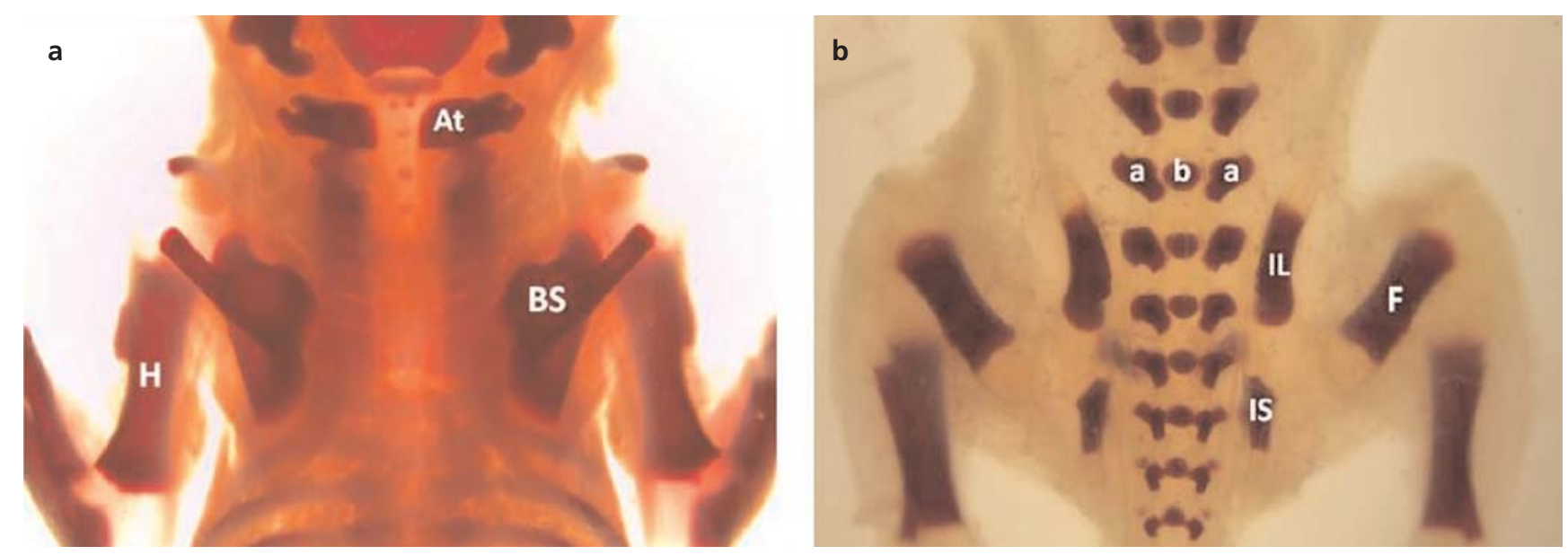

Figure 4. Posterior view of pups born to control female rats stained with alizarin red-S showing. (a) Ossified body of the scapula (BS), atlas vertebra (At) and humerus (H). (b) Ossified body (b) and arch (a) of the vertebrae, ilium (IL), ischium (IS) and femur (F).

observed in some of the bones of the hand and foot in 8 pups out of 97 (18.2\%). Ossification of the skeleton of the remaining pups was almost similar to that found in control group.
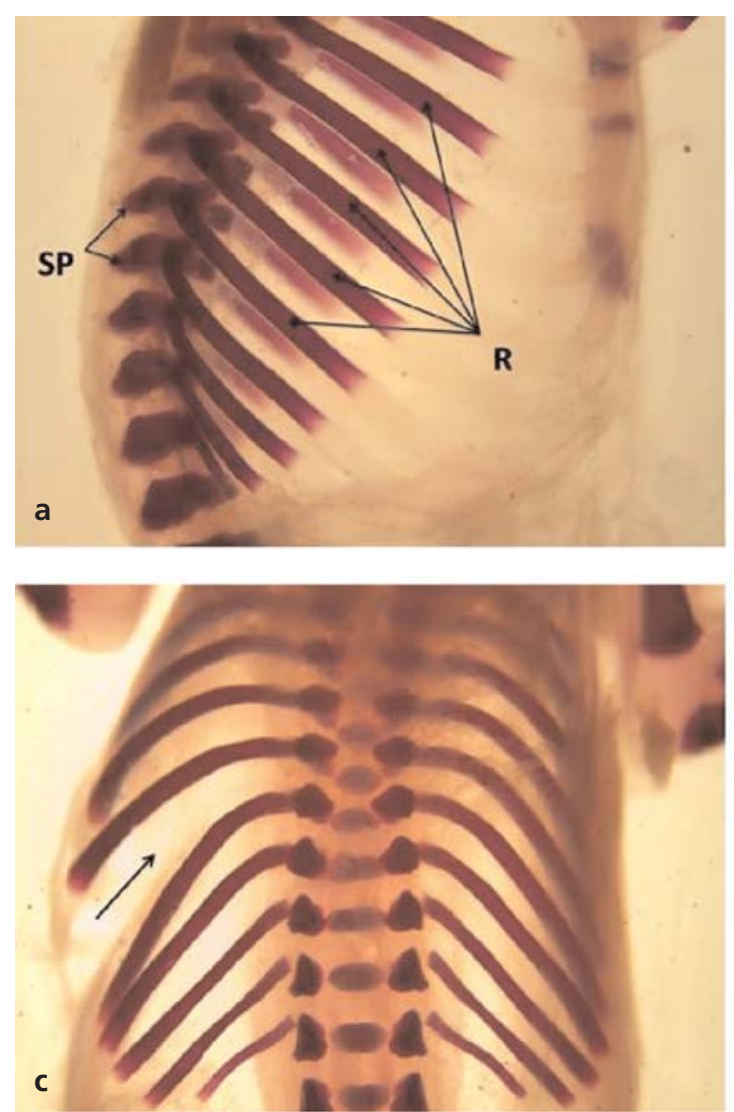

\section{Discussion}

Existing knowledge about the impact of antiepileptic drugs such as PHT on free radical / antioxidant system is poor and controversial. In vivo and in vitro studies indi-
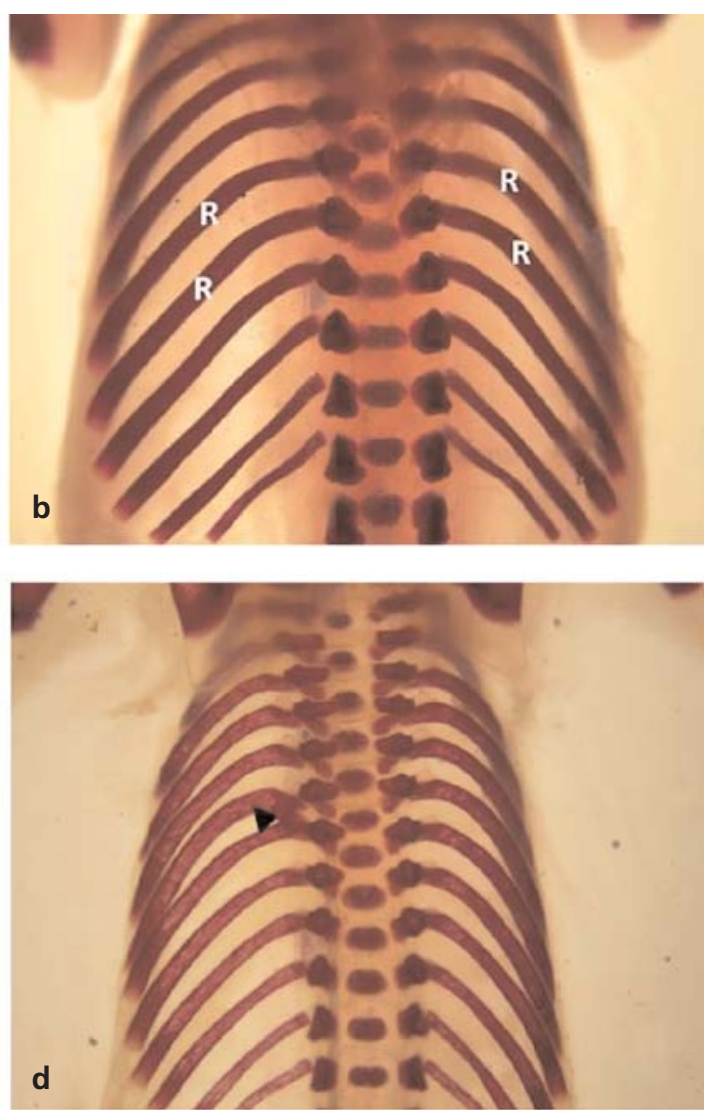

Figure 5. Lateral (a) and posterior (b) views of pups born to control female rats stained with alizarin red-S showing ossified part of the spinous process (SP) and ossified ribs (R); (c, d) Posterior view of pups born to the PHT treated female rats stained with alizarin red-S showing rib separation (arrow) and fusion between two ribs posteriorly (arrow head). 

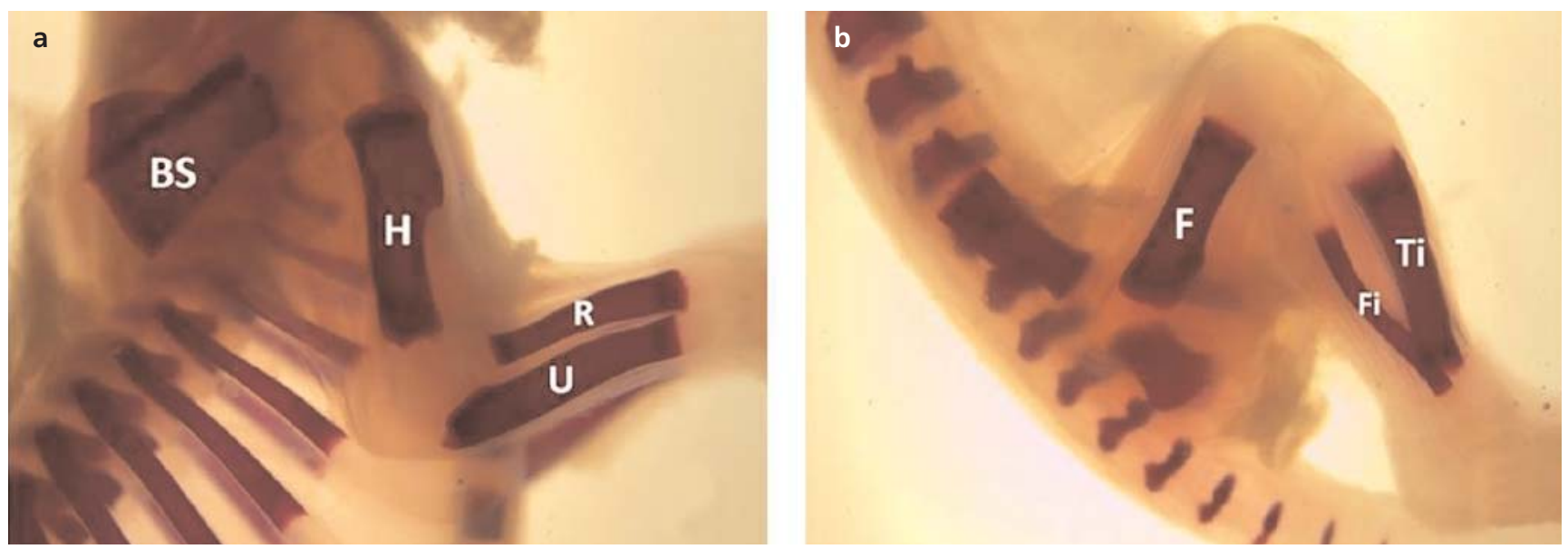

Figure 6. (a, b) Lateral views of pups born to control female rats stained with alizarin red-S showing ossified diaphysis of the humerus (H), ulna $(\mathrm{U})$, radius $(\mathrm{R})$, femur $(\mathrm{F})$, tibia $(\mathrm{Ti})$, fibula $(\mathrm{Fi})$, and body of the scapula (BS).

cated that PHT-initiated teratogenesis may involve, at least in part, peroxidase-catalyzed bioactivation of PHT to a reactive free radical intermediate. If this intermediate is not detoxified, it may initiate oxidative stress leading to oxidation of embryonic lipids, proteins, and
DNA. $^{[35]}$ The authors hypothesized that highly ROS, such as hydroxyl radical, could be generated by the PHT free radical. However, it is known that if these ROS are not detoxified by cytoprotective enzymes or antioxidants, they can cause lipid peroxidation, and protein oxi-
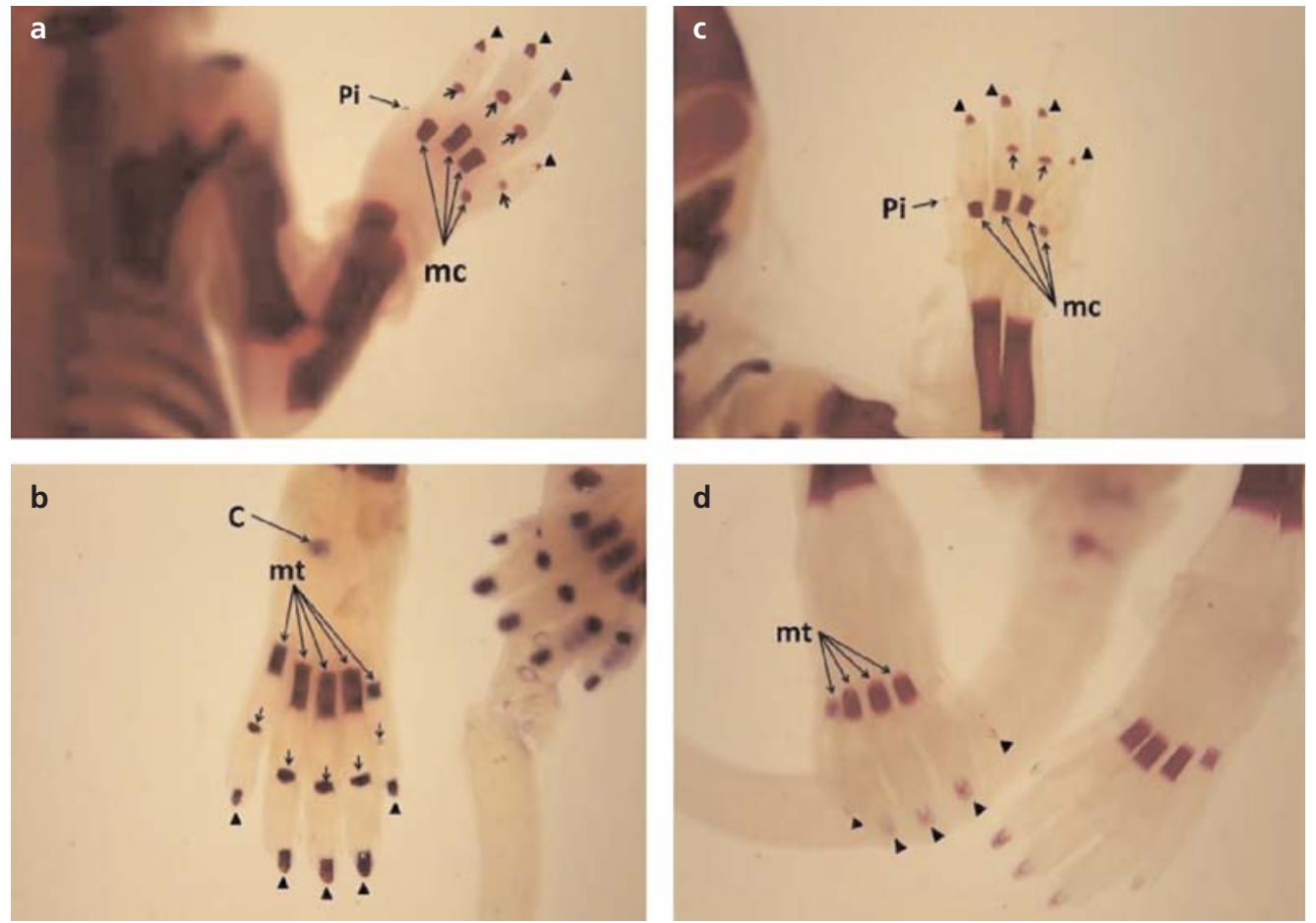

Figure 7. Posterior (a) and anterior (b) views of pups born to control female rats stained with alizarin red-S showing ossification of the pisiform (Pi), the four metacarpals $(\mathrm{mc})$, distal phalanges (arrow heads) and part of the proximal phalanges (short arrows) of the hand; and ossification of the center of the calcaneus (C), ossification of the five metatarsals (mt), the distal phalanges (arrow heads) and part of the proximal phalanges (short arrows) of the foot. Posterior (c) and anterior (d) views of pups born to PHT treated female rats stained with alizarin red-S showing in Figure c faint ossification of the pisiform (Pi); and ossification of the four metacarpals (mc), all distal phalanges (arrow heads) and part of the proximal phalanges (short arrows) of the 2 nd and 3rd fingers of the hand. (d) Ossification of 2nd, 3rd, 4th and 5th metatarsals (mt); and mild (faint) ossification of the distal phalanges (arrow heads). 

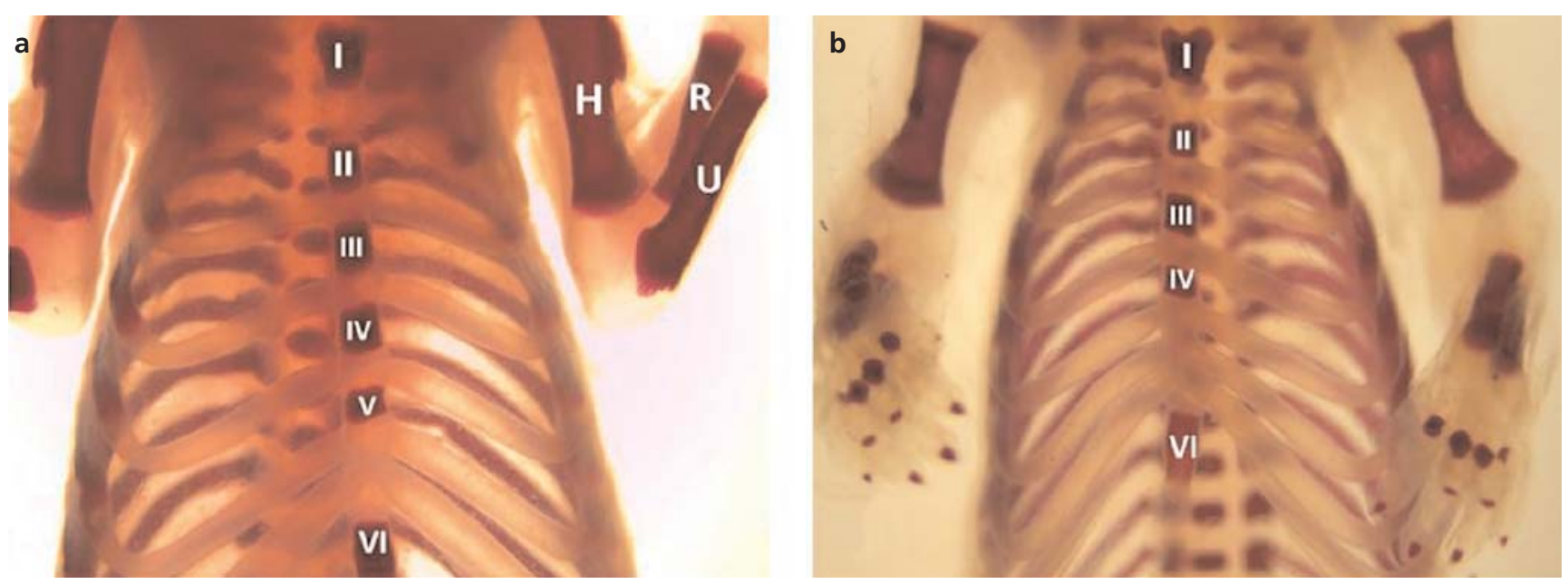

Figure 8. (a) Anterior view of a pup born to control female rat stained with alizarin red-S showing six ossified sternebrae (I, II, III, IV, V, IV). (b) Anterior view of a pup born to PHT treated female rat stained with alizarin red-S showing five ossified sternebrae (I, II, III, IV, VI) with no ossification of the 5th sternebra. $\mathrm{H}$ : humerus; R: radius; U: ulna.

dation and degradation. These changes can lead to structural and functional changes and also to injuries at the biochemical level. ${ }^{[35]}$ Understanding of the biochemical and molecular changes associated with oxidative stress may promote establishment of experimental models for testing drugs protecting tissues from injury. ${ }^{[36]}$

In the present study, PHT injection showed significant higher levels of MDA and NAGA activity and significant lower levels of GSH in maternal plasma and tissues and in their pups' tissues than corresponding levels in controls. Previous studies showed a high teratogenic potential of PHT and neuro-behavioural alterations, accompanied with a broad spectrum of biochemical changes in NAGA activity and GSH level. ${ }^{[37-39]}$ The enhancement of oxidative stress indices in the PHT-treated rats and their pups in our work is in agreement with the findings of Reeta et al. ${ }^{[4]}$ who have reported significantly higher levels of MDA, and significant reduction in the GSH levels in the brain tissue of the rats treated with PHT. Earlier findings found enhanced oxidative stress in the female epileptics receiving PHT compared to controls. ${ }^{[7,4]}$ Oxidative stress due to PHT has been implicated as one of the mechanisms of PHT-initiated toxicity and the fetal hydantoin syndrome. ${ }^{[8,41]}$ Reeta et al ${ }^{[40]}$ reported that the increase in oxidative stress in the PHT-treated animals may be one of the mechanisms of PHT-induced cognitive impairment observed in their study.

Wellfelt et al ${ }^{[42]}$ have hypothesized that the damage effect of the PHT-induced hypoxia in the embryo possibly occurs during the subsequent period of re-oxygenation which is associated with extensive production of free radicals that can damage cellular systems. Findings of Navarova et al. ${ }^{[9]}$ support this hypothesis, since they have reported a decline in oxygen saturation of the blood (about 20\%) in the common iliac artery on the 20th day of gestation in the rats after single intravenous administration of $150 \mathrm{mg} / \mathrm{kg}$ of PHT.

Decisions making about treatment of pregnant epileptic women is difficult due to conflicting risks. These women are at increased risk of complications during pregnancy, and their children are at increased risk of poor outcomes. ${ }^{[43]}$ Females treated with antiepileptic drugs during pregnancy are at increased risk of prematurity, low birth
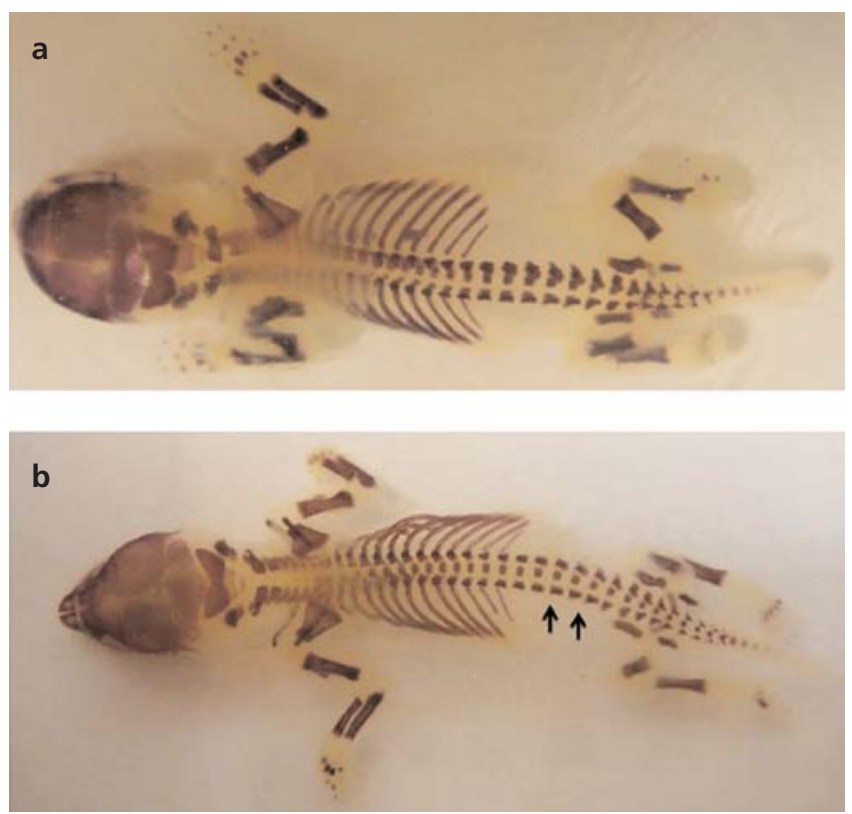

Figure 9. A photograph of the skeletons of a pup born to control female rat (a) and a pup born to PHT treated female rat (b) stained with alizarin red-S showing lateral deviation of the vertebral column at the lumbar region of the skeleton of the pup born to PHT treated rat (short arrows). 
weight neonates, increased fetal and neonatal death rates, congenital malformations and developmental delay. ${ }^{[4]}$ The most common major anatomic abnormalities associated with antiepileptic drugs are orofacial defects (e.g. cleft lip with or without cleft palate), skeletal abnormalities, neural tube defects, heart malformations and urologic defects. ${ }^{[4]}$

In the present study, there was significant reduction in the weight, crown-rump length and number of pups in PHT-treated group compared to the control group. This is in agreement with the finding of Abela et al. ${ }^{[16]}$ and Ata and Sullivan ${ }^{[45]}$ who reported that prenatal treatment of PHT leads to a decrease in the number of fetuses and fetal weight in rats. Likely, many investigators reported that mouse embryonic growth was reduced after maternal administration of PHT. ${ }^{[46-48]}$

Moreover, our study showed maxillary hypoplasia in $13.79 \%$ of pups in PHT-treated group. This is in agreement with the finding of Abela et al. ${ }^{[16]}$ However, Sulik et al. ${ }^{[4]}$ reported that PHT increased incidence of cleft lip (CL) of strains of mice with genetic predisposition to malformation. Furthermore, it has been reported that genetic predisposition is enhanced by maternal hypoxia and reduced by maternal hyperoxemia. ${ }^{[50,51]} \mathrm{CL}$ was not seen in our study; the only explanation put forward, this may be due to the absence of genetic predisposition in the strains of rats used.

In the present study, ossification deteriorations were observed in the skeleton of many pups in PHT-treated group. Most of the skull bones were mildly ossified as compared to the controls. Eluma et al. ${ }^{[46]}$ and Sullivan and Mcelhatton ${ }^{[52]}$ have reported exencephaly in mouse fetuses after giving $125 \mathrm{mg} / \mathrm{kg}$ and $120 \mathrm{mg} / \mathrm{kg}$ PHT respectively, whereas Soysal et al ${ }^{[13]}$ reported ossification malformations mainly confined to the frontal bone in the rat fetuses treated with PHT.

Earlier studies have reported ectrodactily, syndactily and obvious deteriorations in ossification of some phalanges, metacarpal and metatarsal bones in the PHT applied mice and rat. ${ }^{[52-56]}$ Our study recorded deteriorations in ossification of some phalanges, metacarpal and metatarsal bones, but neither ectrodactily nor syndactily was observed. Harbison and Becker ${ }^{[5]]}$ and Mansoor et al. ${ }^{[6]]}$ have reported a worsening in the ossification process of the long bones in the mouse and rat fetuses of the PHT treated mothers, but such a finding was not observed in the present work. Soysal ${ }^{[13]}$ and Mansoor et al. ${ }^{[5]}$ reported costal anomalies in the form of costal separation, while Kim et al. ${ }^{[55]}$ have reported costal anomalies in the form of absent, short and discontinuous ribs, and absent ossification of some sternebrae in the fetuses of PHT treated rats. However, our study showed absence of ossification centre of one sternebra and costal separation in the pups of the PHT-treated mothers. Furthermore, the present study recorded the presence of lumbar scoliosis and fusion between two ribs in the pups born to the PHT-treated mothers. To the best of our knowledge, these results are not reported in the earlier studies.

It has been suggested that detoxification of a xenobiotic free radical intermediate with antioxidants may provide important embryo protection. ${ }^{[5]}$ GSH may be involved in the detoxification of a teratogenic reactive intermediate of PHT and/or in the cytoprotection against oxidative stress. GSH depletors or inhibitors of GSH synthesis potentiate PHT teratogenicity in mice. ${ }^{[57]}$ Winn and Wells ${ }^{[58]}$ stated that maternal administration of the antioxidative enzyme catalase enhanced embryonic activity and inhibited PHT teratogenicity. Vit $\mathrm{E}$ is believed to help in amelioration of diseases associated with oxidative stress; in addition, it is considered safe in pregnancy. ${ }^{[2,21]}$

In the current study, administration of Vit E with PHT during pregnancy caused significant reduction in the levels of MDA and NAGA activity and significant elevation in the levels of GSH in maternal plasma and tissues and in pups' tissues in comparison to corresponding levels in PHT-treated group. These biochemical changes were associated with significant increase in the weight, crownrump length and number of pups in comparison with the pups in PHT-treated group. In this respect, Capper et al. ${ }^{[59]}$ found that supranutritional Vit E supplementation of ewes resulted in a significant increase in lamb birth weight. On the other hand, Boskovic et al ${ }^{[60]}$ reported that consumption of high doses of Vit $\mathrm{E}$ during the first trimester of pregnancy does not appear to be associated with an increased risk for major malformations, but may be associated with decrease in birth weight. Furthermore, Navarova et al. ${ }^{[9]}$ reported that administration of Vit $\mathrm{E}$ during pregnancy did not inhibit the biochemical changes induced by PHT. In our opinion, this may be related to the duration and route of Vit $\mathrm{E}$ administration. Navarova et al. ${ }^{[9]}$ administered Vit $\mathrm{E}$ two hours prior to PHT orally from the day 7 to the day 18 of gestation, while in our study, Vit E was injected IP from day one to day 20 of gestation.

Several investigators stated that PHT-teratogenicity in mice was reduced with free radical scavengers such as Vit E ${ }^{[58]}$ Our study found that pups born to PHT + Vit Etreated mothers have decreased incidence of maxillary hypoplasia and much less ossification impairment of the bones of the skull, hand and foot in comparison with pups born to the PHT-treated mothers. However, ossification pattern of the skeletons of most of the pups born to PHT + Vit E-treated group was almost similar to that of control group. In contrast, Abela et al. ${ }^{[16]}$ stated that high antioxidant diet including Vit $\mathrm{E}$ failed to decrease the incidence of maxillary hypoplasia in the fetuses of PHTtreated mothers. This difference may be due to the difference in the dose and route of administration of Vit $\mathrm{E}$. 


\section{Conclusion}

Administration of pregnant rats with PHT led to increase in the indices of oxidative stress in both maternal and pups' tissues associated with morphometric and morphological changes in the pups in the form of weight, length and number reduction, maxillary hypoplasia, deterioration of ossification and skeletal anomalies. This may clarify that oxidative stress induced by PHT affects embryonic development. The embryo is more susceptible to oxidative stress at key periods in development, and antioxidant defenses are important in modulating oxidative stress-mediated events. Our study suggests that Vit E has the ability to protect maternal and pups organs from PHT induced oxidative damage and teratogenicity in rat pups. Vit E may be useful in reduction of harmful side effects of PHT therapy during pregnancy to ensure optimal outcomes. More studies are needed to determine the effective therapeutic dose and suitable duration of administration of Vit $\mathrm{E}$.

\section{Acknowledgments}

This study was supported by grant (number SR-D-009061) from The Deanship of Scientific Research, Qassim University, Saudi Arabia.

\section{References}

1. Wells PG, McCallum GP, Chen CS, Henderson JT, Lee CJ, Perstin J, Preston TJ, Wiley MJ, Wong AW. Oxidative stress in developmental origins of disease: teratogenesis, neurodevelopmental deficits, and cancer. Toxicol Sci 2009;108:4-18.

2. Thompson J, Doi T, Power E, Balasubramanian I, Puri P, Bannigan J. Evidence against a direct role for oxidative stress in cadmiuminduced axial malformation in the chick embryo. Toxicol Appl Pharmacol 2010;243:390-8.

3. Valko M, Leibfritz D, Moncol J, Cronin MT, Mazur M, Telser J. Free radicals and antioxidants in normal physiological functions and human disease. In J Biochem Cell Biol 2007;39:44-84.

4. Hansen JM, Harris KK, Philbert MA, Harris C. Thalidomide modulates nuclear redox status and preferentially depletes glutathione in rabbit limb versus rat limb. J Pharmacol Exp Ther 2002;300:768-76.

5. Wells PG, Kim PM, Laposa RR, Nicol ChJ, Parman T, Winn LM. Oxidative damage in chemical teratogenesis. Mutat Res 1997; 396:65-78.

6. Ono H, Sakamoto A, Sakura N. Plasma total glutathione concentrations in epileptic patients taking anticonvulsants. Clin Chim Acta 2000;298:135-43.

7. Mahle C, Dasgupta A. Decreased total antioxidant capacity and elevated lipid hydroperoxide concentrations in sera of epileptic patients receiving phenytoin. Life Sci 1997;61:437-43.

8. Winn LM, Kim PM, Nickoloff JA. Oxidative stress-induced homologous recombination as a novel mechanism for phenytoin-initiated toxicity. J Pharmacol Exp Ther 2003;306:523-37.

9. Navarova J, Ujhazy E, Dubovicky M, Mach M. Phenytoin induced oxidative stress in pre-and postnatal rat development - Effect of vitamin $\mathrm{E}$ on selective biochemical variables. Biomed Pap Med Fac Univ Palacky Olomouc Czech Repub 2005;149:325-8.
10. Bhuller Y, Jeng W, Wells PG. Variable in vivo embryoprotective role for ataxia-telangiectasia-mutated against constitutive and phenytoin-enhanced oxidative stress in atm knockout mice. Toxicol Sci 2006;93:146-55.

11. Owoeye O, Adedara IA, Bakare OS, Adeyemo OA, Egun C, Farombi EO. Kolaviron and vitamin E ameliorate hematotoxicity and oxidative stress in brains of prepubertal rats treated with an anticonvulsant phenytoin. Toxicol Mech Methods 2014;24:353-61.

12. Owoeye O, Adedara IA, Adeyemo OA, Bakare OS, Egun C, Farombi EO. Modulatory role of kolaviron in phenytoin-induced hepatic and testicular dysfunctions in Wistar rats. J Diet Suppl 2015;12:105-17.

13. Soysal H, Unur E, Duzler A, Karaca O, Ekinci N. Effects of intraperitoneal administration of the phenytoin on the skeletal system of rat fetus. Seizure 2011;20:187-193.

14. Giavini E, Menegola E. Gene-teratogen chemically induced interactions in congenital malformations. Biol Neonate 2004;85:73-81.

15. Webster WS, Howe AM, Abela D, Oakes DJ. The relationship between cleft lip, maxillary hypoplasia, hypoxia and phenytoin. Curr Pharm Des 2006;12:1431-48.

16. Abela D, Howe AM, Oakes DA, Webster WS. Maternal antioxidant supplementation does not reduce the incidence of phenytoininduced cleft lip and related malformations in rats. Birth Defects Res B Dev Reprod Toxicol 2005;74:201-6.

17. Nilson MF, Ritchie H, Webster WS. The effect on rat embryonic heart rate of $\mathrm{Na}+\mathrm{K}+$, and $\mathrm{Ca} 2+$ channel blockers, and the human teratogen phenytoin, changes with gestational age. Birth Defects Res B Dev Peprod Toxicol 2013;98:416-27.

18. Danielsson BR, Azarbayjani F, Skold AC, Webster WS. Initiation of phenytoin teratogenesis: pharmacologically induced embryonic bradycardia and arrhythmia resulting in hypoxia and possible free radical damage at reoxygenation. Teratology 1997;4:271-81.

19. Sun J, Chen Y, Li M, Ge Z. Role of antioxidant enzyme on ionizing radiation resistance. Free Rad Biol Med 1998;24:586-93.

20. Kappus H, Diplock AT. Tolerance and safety of vitamin E: a toxicological position report. Free Rad Biol Med 1992;13:55-74.

21. Cohen-Kerem R, Koren G. Antioxidants and fetal protection against ethanol teratogenicity. I. Review of the experimental data and implications to humans. Neurotoxicol Teratol 2003;25:1-9.

22. Sastre J, Asens M, Rodrigo F, Pallardo FV, Vento M, Vina J. Antioxidant administration to the mother prevents oxidative stress associated with birth in the neonatal rat. Life Sci 1994;54:2055-9.

23. Turgut M, Başaran O, Cekmen M, Karataş F, Kurt A, Aygün AD. Oxidant and antioxidant levels in preterm newborns with idiopathic hyperbilirubinaemia. J Paediatr Child Health 2004;40:633-7.

24. Rugh R. The mouse: its reproduction and development. 2nd ed. Minneapolis (MN): Burgess Publishing Company; 1968. p. 269-99.

25. Smerdely P, Pitsiavas V, Boyages SC. Methimazole inhibits FTRL-5 thyroid cell proliferation by inducing-S-phase arrest of cell cycle. Endocrinology 1993;133:2403-6.

26. Patton J, Kaufman H. Timing of ossification of limb bones and growth rates of various long bones of the fore and hind limbs of the prenatal and early postnatal laboratory mouse. J Anat 1995;186: 175-85.

27. Ronning $\mathrm{O}$, Kantoma $\mathrm{T}$. The growth pattern of the clavicle in the rat. J Anat 1988;159:173-9.

28. Culling CFA. Handbook of histopathological and histochemical techniques. 3rd ed. London: Butterworths; 1974.

29. Erdogan D, Kadıoğlu D, Peker T. Demostration of congenital anomalies in the joints of the forelimbs and hindlimbs caused by several pharmacological agents. Anat Histol Embryol 1996;25:263-7. 
30. Young AD, Phipps DE, Astroff AB. Large-scale double staining of rat fetal skeletons using alizarin red $\mathrm{S}$ and alcian blue. Teratology 2000;61:273-6.

31. Duzler A, Cakır A. [Postnatal development of the thoracic limb bones in New Zealand rabbit.] Ankara Üniversitesi Veteriner Fakültesi Dergisi 2003;50:165-72. [Turkish]

32. Lowry OH, Rosebrough NJ, Farr AL, Randall RJ. Protein measurement with the Folin phenol reagent. J Biol Chem 1951;193:265-75.

33. Thayer WS. Serum lipid peroxides in rats treated chronically with adriamycin. Biochem Pharmacol 1984;33:2259-63.

34. Dutta P, Seirafi J, Halpin D, Pinto J, Rivlin R. Acute ethanol exposure alters hepatic glutathione metabolism in riboflavin deficiency. Alcohol 1995;12:43-7.

35. Winn LM, Wells PG. Evidence for embryonic prostaglandin H synthase-catalyzed bioactivation and reactive oxygen species mediated oxidation of cellular macromolecules in phenytoin and benzo[a] pyrene teratogenesis. Free Radic Biol Med 1997;22:607-21.

36. Kehrer JP, Lund LG. Cellular reducing equivalents and oxidative stress. Free Radical Biol Med 1994;17:65-75.

37. Dubovicky M, Ujhazy E, Kovacovsk P, Navarova J, Jurani M, Šoltés L. Effect of melatonin on eurobehavioral dysfunctions induced by intrauterine hypoxia in rats. Cent Eur J Public Health 2004;12 Suppl:S23-5.

38. Navarova J, Ujhazy E, Dubovicky M, Mach M. Effect of melatonin on biochemical variables induced by phenytoin in organs of mothers, foetuses and offsprings of rats. Cent Eur J Public Health 2004;12 Suppl:S67-9.

39. Ujhazy E, Mach M, Dubovicky M, Navarova J, Soltes L, Juranek I, Brucknerova I, Zeman M. Effect of melatonin and stobadine on maternal and embryofoetal toxicity in rats due to intrauterine hypoxia induced by phenytoin administration. Cent Eur J Public Health 2004;12 Suppl:S83-6.

40. Reeta KH, Mehla J, Gupta YK. Curcumin is protective against phenytoin-induced cognitive impairment and oxidative stress in rats. Brain Research 2009;1301:52-60.

41. Liu CS, Wu HM, Kao SH, Wei YH. Phenytoin-mediated oxidative stress in serum of female epileptics: a possible pathogenesis in the fetal hydantoin syndrome. Hum Exp Toxicol 1997;16:177-81.

42. Wellfelt K, Skold AC, Wallin A, Danielsson BR. Teratogenicity of the class III antiarrhythmic drug almokalant: role of hypoxia and reactive oxygen species. Reprod Toxicol 1999;13:93-101.

43. Pennell PB. Pregnancy in women who have epilepsy. Neurol Clin 2004;22:799-820

44. Meador KJ, Baker GA, Finnell RH, Kalayjian LA, Liporace JD, Loring DW, Mawer G, Pennell PB, Smith JC, Wolff MC; NEAD Study Group. In utero antiepileptic drug exposure: fetal death and malformations. Neurology 2006;67:407-12.

45. Ata MM, Sullivan FM. Effect of prenatal phenytoin treatment on postnatal development Br J Pharmacol 1977;59:494P.
46. Eluma FO, Sucheston ME, Hayes TG, Paulson RB. Teratogenic effects of dosage levels and time of administration of carpamazepine, sodium valproate and diphenylhydantoin on craniofacial development in the CD-1 mouse fetus. J Craniofac Gen Dev Biol 1984;4:191-210.

47. Hicks HE, Spalding PM, Banes AJ. The water, DNA, collagen and noncollagen protein contents in embryos after maternal administration of a teratogenic dose of phenytoin. Toxicol Lett 1985;25: $41-6$.

48. Hansen DK, Billings RE. Effect of route of administration on phenytoin teratogenicity in A/J mice. J Craniofac Gen Dev Biol 1986;6:131-8.

49. Sulik KK, Johnston MC, Ambrose LJ, Dorgan D. Phenytoin dilantin-induced cleft lip and palate in A/J mice: a scanning and transmission electron microscopic study. Anat Rec 1979;195:243-55.

50. Millicovsky G, Johnston MC. Maternal hypoxia greatly reduces the incidence of phenytoin-induced cleft lip and palate in $\mathrm{A} / \mathrm{J}$ mice. Science 1981;212:671-72.

51. Millicovsky G, Johnston MC. Hyperoxia and hypoxia in pregnancy: simple experimental manipulation alters the incidence of cleft lip and palate in $\mathrm{Cl} / \mathrm{Fr}$ mice. Proc Natl Acad Sci U S A 1981;78:5722-23.

52. Sullivan FM, Mcelhatton PR. Teratogenic activity of the antiepileptic drugs phenobarbital. phenytoin and primidone in mice. Toxicol Appl Pharmacol 1975;34:271-82.

53. Harbison RD, Becker BA. Diphenylhydantoin teratogenicity in rats. Toxicol Appl Pharmacol 1972;22:193-200.

54. Hanson JW. Teratogen update: fetal hydantoin effects. Teratology 1986;33:349-53.

55. Kim SH, Lee IC, Baek HS, Lim JH, Moon C, Shin DH, Kim SH, Park SC, Kim JC. Dose-response effects of diphenylhydantoin on pregnant dams and embryo-fetal development in rats. Birth Defects Res B Dev Reprod Toxicol 2012;95:337-45.

56. Mansoor MA, Sewelam AS, Abdul Rahman MM, Sabry MA. A model for the study of induced skeletal anomalies in albino rat fetuses. J Am Sci 2014;10:181-90.

57. Wong M, Wells PG. Modulation of embryonic glutathione reductase and phenytoin teratogenicity by 1, 3-bis(2-chloroethyl)-1nitrosourea. J Pharmacol Exp Ther 1989;250:336-42.

58. Winn LM, Wells PG. Maternal administration of superoxide dismutase and catalase in phenytoin teratogenicity. Free Rad Biol Med 1999;26:266-74.

59. Capper JL, Wilkinson RG, Kasapidou E, Pattinson SE, Mackenzie AM, Sinclair LA. The effect of dietary vitamin E and fatty acid supplementation of pregnant and lactating ewes on placental and mammary transfer of vitamin E to the lamb. Br J Nutr 2005;93:549-57.

60. Boskovic R, Gargaun L, Oren D, Djulus J, Koren G. Pregnancy outcome following high doses of Vitamin E supplementation. Reprod Toxicol 2005;20:85-8.

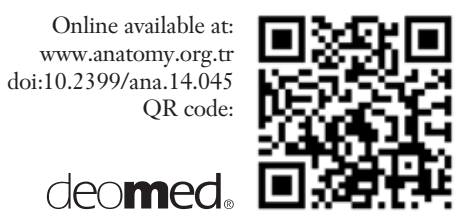

Correspondence to: Tarek Mohamed Essa, MD Department of Anatomy, Faculty of Medicine, Alexandria University, Alexandria, Egypt Phone: +96 6507970872

e-mail: tarek_essa612000@yahoo.com

Conflict of interest statement: No conflicts declared.

\footnotetext{
This is an open access article distributed under the terms of the Creative Commons Attribution-NonCommercial-NoDerivs 3.0 Unported (CC BY-NCND3.0) Licence (http://creativecommons.org/licenses/by-nc-nd/3.0/) which permits unrestricted noncommercial use, distribution, and reproduction in any medium, provided the original work is properly cited. Please cite this article as: Essa TM, Gabr AM, Mohamed AEE, Meki AMA. Protective effect of maternal vitamin E supplementation on phenytoin-induced teratogenicity in rat pups. Anatomy 2015;9(1):1-12.
} 